九州大学学術情報リポジトリ

Kyushu University Institutional Repository

\title{
Single-crystalline (100) Ge networks on insulators by rapid-melting growth along hexagonal mesh-pattern
}

Toko, Kaoru

Department of Electronics, Kyushu University

Ohta, Yasuharu

Department of Electronics, Kyushu University

Sakane, Takashi

Department of Electronics, Kyushu University

Sadoh, Taizoh

Department of Electronics, Kyushu University

他

http://hdl. hand le. net/2324/25530

出版情報: Applied Physics Letters. 98 (4)，pp.042101(1)-042101(3)，2011-01. American Institute of Physics

バージョン :

権利関係: (C) 2011 American Institute of Physics 


\title{
Single-crystalline (100) Ge networks on insulators by rapid-melting growth along hexagonal mesh-pattern
}

\author{
Kaoru Toko, ${ }^{1, a)}$ Yasuharu Ohta, ${ }^{1}$ Takashi Sakane, ${ }^{1}$ Taizoh Sadoh, ${ }^{1}$ Ichiro Mizushima, ${ }^{2}$ and \\ Masanobu Miyao ${ }^{1, b)}$ \\ ${ }^{1}$ Department of Electronics, Kyushu University, 744 Motooka, Fukuoka 819-0395, Japan \\ ${ }^{2}$ Semiconductor Technology Academic Research Center, 3-17-2 Shinyokohama, Yokohama 220-0033, Japan
}

(Received 9 November 2010; accepted 29 December 2010; published online 24 January 2011)

\begin{abstract}
Single-crystalline-Ge (c-Ge) networks on insulator films formed on $\mathrm{Si}$ substrates are essential for integrating high-speed and multifunctional devices onto the Si-platform. Rapid-melting-growth of mesh-patterned amorphous-Ge is examined over large areas $\left(500 \times 250 \mu \mathrm{m}^{2}\right)$. For squared-mesh-pattern, polycrystalline-Ge forms throughout most of the mesh, though c-Ge is obtained near $(<100 \mu \mathrm{m})$ Si-seed. Based on the consideration of geometric-effects, mesh-patterns are changed to hexagonal. This realizes c-Ge networks over the entire insulator area. These results indicate that $\mathrm{Ge}$ growth initiated from Si-seed propagates laterally over the hexagonal-mesh-pattern though bending and branching. These unique c-Ge-networks on insulators facilitate Ge-based advanced-devices on the Si-platform. (C) 2011 American Institute of Physics.
\end{abstract}

[doi:10.1063/1.3544057]

Single-crystalline-Ge (c-Ge) thin-films $(<100 \mathrm{~nm})$ on insulators (GOI) are essential structures for achieving advanced high-speed transistors with high carrier mobilities, low parasitic capacitances, and low junction leakage currents. ${ }^{1-3}$ The oxidation-induced $\mathrm{Ge}$ condensation process ${ }^{4,5}$ and wafer bonding techniques ${ }^{6}$ have been developed. However, the former has low carrier mobility $\left(410 \mathrm{~cm}^{2} / \mathrm{V} \mathrm{s}\right),{ }^{5}$ which is caused by oxidation-induced point-defects. In the latter, the fabrication process of the $\mathrm{Ge}$ thin films is complex.

Recently, seeded rapid-melting-growth of amorphous-Ge $(a-\mathrm{Ge})$ has been investigated. This enabled the growth of defect-free single-crystalline (100) GOI strips that are $20-40 \mu \mathrm{m}$ long and $2-3 \mu \mathrm{m}$ wide. ${ }^{7-10}$ The monolithic integration of GOI transistors with $\mathrm{Si}$ transistors on a $\mathrm{Si}$ substrate was also demonstrated. ${ }^{11}$ Our efforts in the past several years have focused on the mechanism of this growth. ${ }^{12}$ This has enabled the optimization of both sample structures and annealing conditions. As a result, giant (100), (110), and (111) GOI strips $(>400 \mu \mathrm{m})$, which are over one order of magnitude longer than previously achieved. ${ }^{12,13}$ Moreover, we demonstrated very high hole mobility $\left(\sim 1100 \mathrm{~cm}^{2} / \mathrm{V} \mathrm{s}\right),{ }^{13-15}$ which indicates high GOI crystal quality. These results have caused the expectation that high mobility Ge transistors will be integrated with Si largescale integrated circuits.

However, formation of uniform and flat c-Ge strip arrays is difficult because of Ge aggregation during the melt-back process. This has limited the strip width to less than $5 \mu \mathrm{m}$. Consequently, Ge transistors must be fabricated on the narrow Ge strip arrays. This is an impediment to achieving high-density Ge transistor circuits. A possible solution to obtain large-area GOI is the formation of Ge networks composed of crossing strips, i.e., the mesh-pattern, which has not been studied yet.

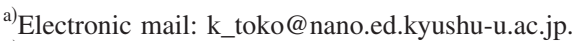

${ }^{b)}$ Electronic mail: miyao@ed.kyushu-u.ac.jp.
}

This paper describes the seeded rapid-melting growth of Ge along these mesh-patterned structures. The influence of bending and branching during lateral growth specific for this structure are comprehensively studied. This enables c-Ge networks with a hexagonal mesh-pattern to cover a large area $\left(500 \times 250 \mu \mathrm{m}^{2}\right)$.

In the experiments, $\mathrm{Si}(100)$ substrates $(600 \mu \mathrm{m}$ thickness) covered with $\mathrm{Si}_{3} \mathrm{~N}_{4}$ films (100 nm thickness) were used. These films were patterned using wet etching to form seeding areas $\left(50 \times 300 \mu \mathrm{m}^{2}\right)$. The edges of the seeding areas were formed perpendicular to the $\langle 011\rangle$ direction. Subsequently, 100 -nm-thick $a$-Ge layers were deposited using a molecular-beam epitaxy (MBE) system, with a base pressure of $5 \times 10^{-10}$ Torr. They were patterned into a square mesh (Ge strip width: $3 \mu \mathrm{m}$ and openings: $5 \times 5 \mu \mathrm{m}^{2}$ ). The sample structure is schematically shown in Fig. 1(a). Then, an 800-nm-thick $\mathrm{SiO}_{2}$ layer was deposited using RFmagnetron sputtering. Finally, these samples were heattreated using pre-heating $\left(800{ }^{\circ} \mathrm{C}, 1 \mathrm{~min}\right)$ followed by rapid

(a)

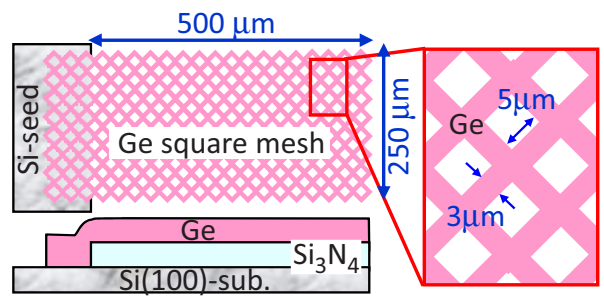

(b)

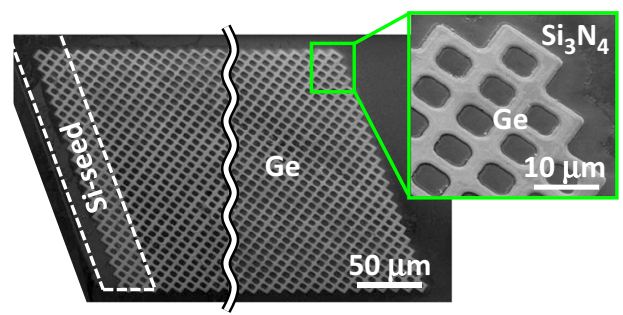

FIG. 1. (Color online) (a) Schematic sample structure with the square meshpattern. (b) SEM images of a GOI sample after RTA $\left(1000{ }^{\circ} \mathrm{C}, 1 \mathrm{~s}\right)$. 
(a)

(b)

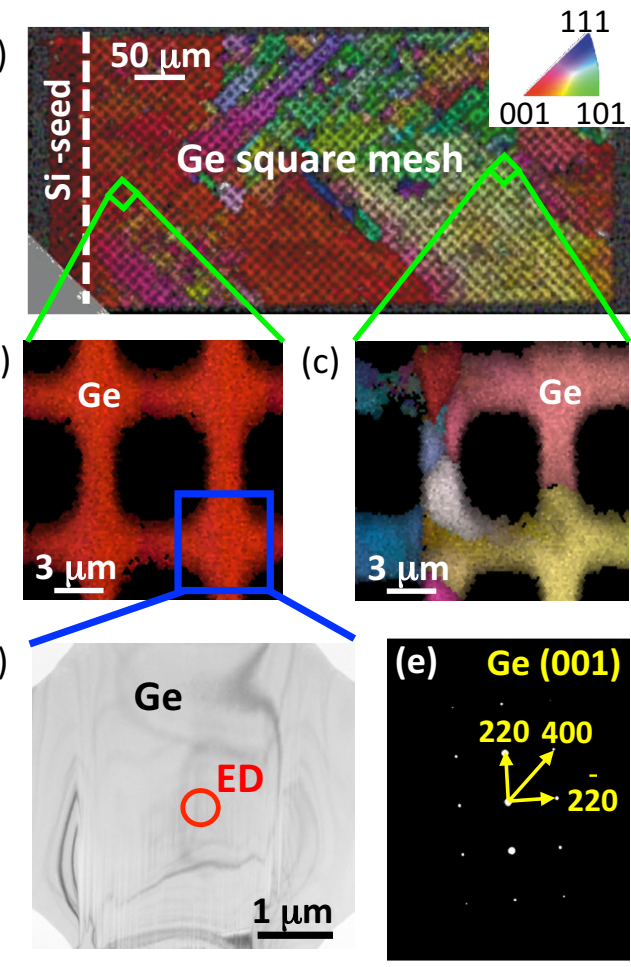

FIG. 2. (Color online) (a) EBSD image of a GOI sample over the entire mesh-pattern region $\left(500 \times 250 \mu \mathrm{m}^{2}\right)$. Magnified images (b) near and (c) far from the seeding region after RTA $\left(1000{ }^{\circ} \mathrm{C}, 1 \mathrm{~s}\right)$. (d) TEM image and (e) ED pattern of a single-crystalline GOI sample at a crossing region of the mesh-pattern.

thermal annealing (RTA) at $1000{ }^{\circ} \mathrm{C}(1 \mathrm{~s})$. This process was used to induce the melting growth from the seeding areas, i.e., from the $\mathrm{Si}$ substrate. The surface morphology, crystal orientation, and crystal quality of the grown layers were characterized using scanning electron microscopy (SEM), electron backscattering diffraction (EBSD), and plane-view transmission electron microscopy (TEM). The $\mathrm{SiO}_{2}$ capping layers were removed before these measurements.

SEM images of the annealed sample are shown in Fig. 1(b), which show the uniform and flat Ge surface that lacks Ge aggregation. The crystal orientation map for the entire area obtained using the EBSD measurements is shown in Fig. 2(a). Magnified EBSD images of the Ge network both near and far from the Si-seed are shown in Figs. 2(b) and 2 (c), respectively. These results indicate that Ge growth initiated from $\mathrm{Si}(100)$ seed propagates laterally along the mesh-patterned Ge. The lateral growth extends $100 \mu \mathrm{m}$ from the Si-seed. However, significant changes in the $\mathrm{Ge}$ orientation occur for the regions far $(>100 \mu \mathrm{m})$ from the $\mathrm{Si}$-seed. This results in the formation of polycrystalline $\mathrm{Ge}$, as shown in Fig. 2(c). Such phenomena will be discussed later.

Note that no grain boundaries are detected in the magnified EBSD image in Fig. 2(b), even though at least one collision of melting growth-front must exist in this area. Similar results were reported for the lateral vapor-phase epitaxy of $\mathrm{Ge}$, where two fronts of lateral growths that were initiated from different positions on the same Si-substrate, collided on the $\mathrm{SiO}_{2}$ without generating visible defects. ${ }^{16,17}$ These results suggest that $\mathrm{Ge}$ melting-growth initiated from the Sisubstrate propagates while maintaining its orientation perfectly, as reported for lateral vapor-phase epitaxy. ${ }^{16,17}$ The

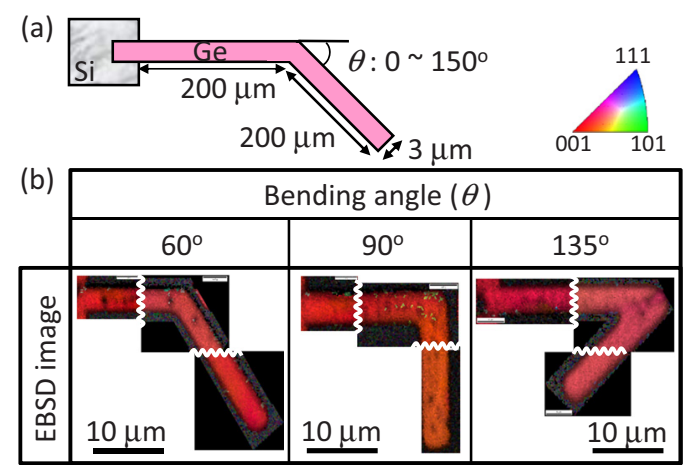

FIG. 3. (Color online) (a) Schematic sample structure of the Ge strip with a single-bending pattern. (b) EBSD images of annealed samples $\left(1000^{\circ} \mathrm{C}, 1\right.$ s) with bending angles of $60^{\circ}, 90^{\circ}$, and $135^{\circ}$.

TEM images shown in Fig. 2(d) reveal no dislocation or stacking fault in the crossing region, even though strainoriginated black lines are visible. In addition, the electron diffraction (ED) pattern shown in Fig. 2(e) exhibits clear spots of (100) Ge, indicating coherent lateral growth from the (100) Si-substrate. These results suggest that the crystal quality of the (100) GOI grown along mesh-pattern is as high as that of the straight strip-patterns reported in our previous work. $^{12-15}$

Now, let us consider the polycrystallization phenomena shown in the region far $(>100 \mu \mathrm{m})$ from the Si-seed [Fig. 2(c)], which have never been observed in lateral (100) Ge growth when using the straight strip-pattern. The meshpattern differs from the strip-pattern geometrically because of its existence of bending and branching during lateral growth. Consequently, influence of the bending during growth on the crystal quality is studied as a first step. Here, new strip-patterns with bending structures (total strip lengths: $400 \mu \mathrm{m}$, bending angles $(\theta): 60^{\circ}, 90^{\circ}$, and $135^{\circ}$ ) are employed. This is shown in Fig. 3(a). EBSD images taken after annealing are shown in Fig. 3(b). These images clearly indicate that the lateral Ge growth for all samples propagates over $400 \mu \mathrm{m}$ without a change in orientation. These results clearly indicate that bending of growth direction encountered in mesh-patterned growth is not the main reason for making polycrystalline Ge shown in Fig. 2(c).

The branching during lateral growth is another factor to be examined. Generally, melting growth generates latent heat at the solid-liquid interface, i.e., a growth-front, which flows into the solid-Ge region. When the lateral growth-front arrives at the branching-region, the number of solid-liquid interfaces increases. Consequently, the flux of heat-flow from liquid to solid Ge is increased through the branching, which decreases the cooling rate at the growth-front. This retarded melt-back growth at each branching region prolongs the melting-time in the liquid-Ge in regions far from the seed. This enhances the probability of random spontaneous nucleation, which results in polycrystallization. In Fig. 2(c), polycrystallization in a square mesh-pattern, where one growthfront branches into three at each crossing point, can be observed (branching number: 3). However, polycrystallization was not observed for (100) Ge growth along strippattern (branching number: 1). ${ }^{12,13}$ Therefore, experiments with a branching number of two could be of special interest.

To study this, additional experiments using a hexagonaltype mesh-pattern (branching number: 2) are carried out. The 
(a)

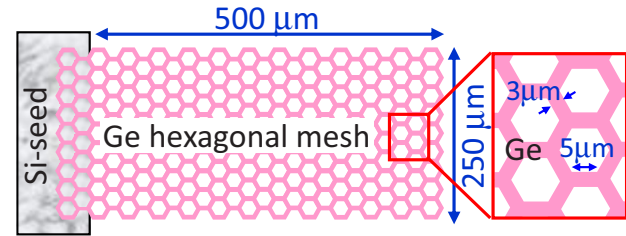

(b)

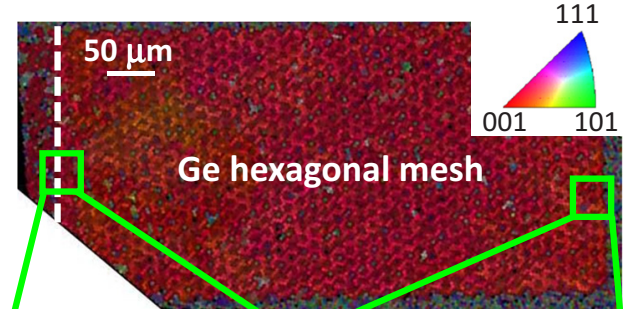

(c)

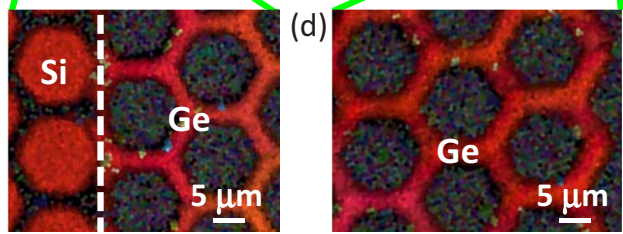

FIG. 4. (Color online) (a) Schematic sample structure with a hexagonal mesh-pattern. (b) EBSD image of a GOI sample over the entire meshregion. Magnified images (c) near and (d) far from the Si-seed after RTA $\left(1000{ }^{\circ} \mathrm{C}, 1 \mathrm{~s}\right)$

sample structure is schematically shown in Fig. 4(a), and EBSD images taken after annealing are shown in Figs. 4(b)-4(d). These EBSD images show the crystal orientation over the entire region [Fig. 4(b)], near the Si-seed [Fig. 4(c)], and near the edge of the mesh-pattern [Fig. 4(d)]. These results indicate that Ge growth initiated from the (100) Si-seed propagates along the hexagonal-type mesh-pattern while keeping its orientation. This enables the complete (100) crystallization of the entire region $\left(500 \times 250 \mu \mathrm{m}^{2}\right)$. This lateral growth has been confirmed by more than 10 samples. In this way, large-area $\left(500 \times 250{\left.\mu \mathrm{m}^{2}\right)}^{2}\right.$ single-crystalline (100) GOI networks composed of crossing strips are possible to grow.

In summary, the seeded rapid-melting growth of $\mathrm{Ge}$ along a mesh-pattern has been studied on insulating films. Lateral growth propagates $100 \mu \mathrm{m}$ from the Si-seed along a square-type mesh-pattern. However, polycrystalline Ge gradually forms. The bending of the growth direction is found not to be the reason for the polycrystallization. The latent heat generated at each of the branching positions prolongs the melting-time of the liquid-Ge, which enhances the

probability of random spontaneous nucleation. To decrease the branching-number, a hexagonal-type mesh is substituted for the square mesh. This enables the growth of singlecrystalline (100) GOI over the entire mesh region (500 $\times 250 \mu \mathrm{m}^{2}$ ). These $\mathrm{c}-\mathrm{Ge}$ networks formed on insulating films will be useful for the development of Ge-based advanced devices on the Si platform.

A part of this work was supported by Semiconductor Technology Academic Research Center (STARC) and a Grant-in-Aid for Scientific Research from the Ministry of Education, Culture, Sports, Science, and Technology in Japan. Also, we greatly appreciate the stimulating comments by Dr. N. Tamura and Dr. M. Yoshimaru of STARC.

${ }^{1}$ M. Miyao, E. Murakami, H. Etoh, K. Nakagawa, and A. Nishida, J. Cryst. Growth 111, 912 (1991)

${ }^{2}$ C. H. Lee, T. Nishimura, N. Saido, K. Nagashio, K. Kita, and A. Toriumi, Tech. Dig. - Int. Electron Devices Meet. 2009, 457.

${ }^{3}$ T. Maeda, K. Ikeda, S. Nakaharai, T. Tezuka, N. Sugiyama, Y. Moriyama, and S. Takagi, IEEE Electron Device Lett. 26, 102 (2005).

${ }^{4}$ N. Sugiyama, T. Tezuka, T. Mizuno, M. Suzuki, Y. Ishikawa, N. Shibata, and S. Takagi, J. Appl. Phys. 95, 4007 (2004).

${ }^{5}$ T. Maeda, K. Ikeda, S. Nakaharai, T. Tezuka, N. Sugiyama, Y. Moriyama, and S. Takagi, Thin Solid Films 508, 346 (2006).

${ }^{6}$ T. Akatsu, C. Deguet, L. Sanchez, F. Allibert, D. Rouchon, T. Signamarcheix, C. Richtarch, A. Boussagol, V. Loup, F. Mazen, J.-M. Hartmann, Y. Campidelli, L. Clavelier, F. Letertre, N. Kernevez, and C. Mazure, Mater. Sci. Semicond. Process. 9, 444 (2006).

${ }^{7}$ Y. Liu, M. D. Deal, and D. Plummer, Appl. Phys. Lett. 84, 2563 (2004).

${ }^{8}$ D. J. Tweet, J. J. Lee, J. S. Maa, and S. T. Hsu, Appl. Phys. Lett. 87, 141908 (2005).

${ }^{9}$ S. Balakumar, M. M. Roy, B. Ramamurthy, C. H. Tung, G. Fei, S. Tripathy, C. Dongzhi, R. Kumar, N. Balasubramanian, and D. L. Kwong, Electrochem. Solid-State Lett. 9, G158 (2006).

${ }^{10}$ T. Hashimoto, C. Yoshimoto, T. Hosoi, T. Shimura, and H. Watanabe, Appl. Phys. Express 2, 066502 (2009)

${ }^{11}$ J. Feng, Y. Liu, P. B. Griffin, and J. D. Plummer, IEEE Electron Device Lett. 27, 911 (2006).

${ }^{12}$ M. Miyao, T. Tanaka, K. Toko, and M. Tanaka, Appl. Phys. Express 2 , 045503 (2009).

${ }^{13}$ K. Toko, T. Tanaka, Y. Ohta, T. Sadoh, and M. Miyao, Appl. Phys. Lett. 97, 152101 (2010).

${ }^{14}$ M. Miyao, K. Toko, T. Tanaka, and T. Sadoh, Appl. Phys. Lett. 95 022115 (2009)

${ }^{15}$ K. Toko, M. Kurosawa, H. Yokoyama, N. Kawabata, T. Sakane, Y. Ohta, T. Tanaka, T. Sadoh, and M. Miyao, Appl. Phys. Express 3, 075603 (2010)

${ }^{16}$ V. D. Cammilleri, V. Yam, F. Fossard, C. Renard, D. Bouchier, P. F. Fazzini, and M. Hÿtch, J. Appl. Phys. 106, 093512 (2009).

${ }^{17}$ H. Y. Yu, S. 1. Cheng, J. H. Park, A. K. Okyay, M. C. Onbaşl1, B. Ercan, Y. Nishi, and K. C. Saraswat, Appl. Phys. Lett. 97, 063503 (2010). 